Научная статья

УДК 338.48

DOI $10.18101 / 2304-4446-2021-3-8-18$

\title{
КОНЦЕССИИ В СФЕРЕ ТУРИЗМА В НАЦИОНАЛЬНЫХ ПАРКАХ: ОСОБЕННОСТИ И ЭТАПЫ РАЗРАБОТКИ
}

\section{(C) Бардаханова Таисия Борисовна}

доктор экономических наук, ведущий научный сотрудник, Байкальский институт природопользования СО РАН Россия, 670047, г. Улан-Удэ, ул. Сахьяновой, 8 tbard@binm.ru

\section{(C) Шаралдаева Виктория Дамдиновна} кандидат биологических наук, доцент, Восточно-Сибирский государственный университет технологий и управления Россия, 670013, г. Улан-Удэ, ул. Ключевская, 40в sharvd@mail.ru

\section{(C) Максанова Людмила Бато-Жаргаловна} доктор экономических наук, доцент, старший научный сотрудник, Байкальский институт природопользования СО РАН Россия, 670047, г. Улан-Удэ, ул. Сахьяновой, 8 lmaksanova@yandex.ru

Аннотация. Авторы статьи рассматривают суть и особенности туристических концессий в национальных парках, ключевые моменты и компоненты системы концессий на основе адаптации ряда аналитических материалов и руководств для менеджеров, обобщающих опыт передовых практик зарубежных стран по подготовке и использованию концессий в туризме на охраняемых территориях. Изучены проблемы, сильные и слабые стороны существующих практик применения концессионных механизмов, различные аспекты планирования и управления концессионной деятельностью для максимизации финансовых, экономических и социальных выгод от работы с частным сектором для достижения целей сохранения биоразнообразия в долгосрочной перспективе. Выделено три основных этапа, отличающихся разными целями и содержанием работ: 1) определение масштабов работ в конкретном национальном парке; 2) проектирование программы концессий и подготовка технико-экономического обоснования; 3) подготовка к закупке (включая стратегию и пакет, рекламные материалы и тендерные документы) и сам процесс переговоров. Сформулированы первоочередные рекомендации по подготовке и применению надежной системы концессий в сфере туризма в национальных парках России.

Ключевые слова: государственно-частное партнерство, концессии, концессионные соглашения, национальный парк.

Благодарность. Исследование выполнено при финансовой поддержке РФФИ в рамках научного проекта № 20-010-00665.

\section{Для цитирования}

Бардаханова Т. Б., Шаралдаева В. Д., Максанова Л. Б.-Ж. Концессии в сфере туризма в национальных парках: особенности и этапы разработки // Вестник Бурятского государственного университета. Экономика и менеджмент. 2021. № 3. С. 8-18. 
Т. Б. Бардаханова, В. Д. Шаралдаева, Л. Б.-Ж. Максанова. Концессии в сфере туризма в национальных парках: особенности и этапы разработки

\section{1 Введение}

Туризм на особо охраняемых природных территориях (ООПТ) призван не только обеспечивать людям интересный отдых на природе, но и демонстрировать образцы грамотного отношения к природе, учить понимать, ценить окружающую среду, бережно к ней относиться, и, наконец, формировать понимание роли охраняемой территории и для самой природы, и для общества [1]. Устойчивый туризм на ООПТ требует способности развивать и продавать туристические продукты на основе того, что может предложить охраняемая территория, и способности поддерживать качество этих территорий для постоянного использования в будущем. Государственно-частное партнерство (ГЧП) в сфере туризма одно из многообещающих решений, которое могло бы побудить частный сектор играть более активную роль в поддержании национальных парков без дополнительного бремени для налогоплательщиков. При этом «частный сектор» может быть коммерческим предприятием или некоммерческой организацией $[2$, с. 80].

В разных странах имеется успешная практика использования частных концессионеров для управления национальными парками в целом или предоставления отдельных туристско-рекреационных услуг (размещение в кемпингах и в зонах дневного отдыха, спортивно-развлекательные мероприятия, сувенирные магазины, общественное питание, заправочные станции и т. п.) [3; 4]. Например, в США - Колорадо, Калифорнии, Орегоне, Вашингтоне и других штатах - на долю концессий приходится до 15\% земель национальных парков, в ЮАР всемирно известен парк имени Крюгера. Хорошо известен положительный опыт развития механизмов концессий в Канаде, Австралии, Новой Зеландии, Намибии, Мозамбике, Галапагосских островах и других странах [5]. Как отмечается в работе [6, с. 6], «доходы от концессий не только напрямую поддерживают управление парками, но также увеличивают доходы и занятость населения, расширяют возможности женщин и дают молодым людям возможность встретиться с людьми из многих стран, обменяться мыслями и разговорами и расширить кругозор». Тема моделей концессий и развития ГЧП приобретает особую актуальность в современных «постковидных» условиях, поскольку все страны стремятся диверсифицировать свои потоки доходов за счет туризма.

Применение механизмов ГЧП при создании объектов туристической инфраструктуры активизируется и в России. Однако примеры использования механизмов ГЧП на отечественных ООПТ, в частности в национальных парках, отсутствуют [7]. Как показано в ранее выполненной работе [8], действующим законодательством не определена роль ООПТ как особого участника ГЧП и отсутствуют нормы о возможности передачи частному партнеру или концессионеру объектов инфраструктуры, находящихся под управлением ООПТ, являющихся федеральными государственными бюджетными учреждениями.

Целью и задачами настоящего исследования являются выявление сути и особенностей концессий в сфере туризма в национальных парках, ключевых моментов и компонентов системы концессий, последовательности и содержания работ по подготовке концессионных соглашений, а также разработка первоочередных рекомендаций по формированию надежной системы туристических концессий в национальных парках России. 


\section{2 Материалы и методы}

В основу исследования положены нормативные правовые документы различных уровней, имеющиеся в открытом доступе, аналитические материалы и руководства, подготовленные по заказу международных организаций (Программа развития ОOH (UNEP), Группа Всемирного банка (The World Bank Group), Международный союз охраны природы (IUCN) и др.), а также научные статьи зарубежных и отечественных ученых и ряд собственных наработок авторов. При проведении исследования обращалось внимание на кейс-стади в области применения концессий в сфере туризма в национальных парках зарубежных стран.

\section{3 Результаты и обсуждение}

3.1 Сущность и особенности туристических концессий в национальных парках

Термин «концессия» образован от латинского слова concessio, которое означает разрешение, согласие, уступка. В энциклопедическом словаре Брокгауза и Эфрона 1895 г. под концессией понималось дозволение компетентной власти на устройство такого промышленного предприятия, которое по закону требует предварительного разрешения правительства [9]. В настоящее время в литературе встречается многообразие определений концессии.

Концессионное управление охраняемыми территориями в некоторых странах - это очень крупный бизнес, связанный с доходами в миллионы долларов и привлечением персонала в сотни сотрудников. В других странах это гораздо меньший бизнес, но не менее важный, поскольку деятельность даже одного концессионера в сельской местности может помочь прокормить ряд местных жителей и сократить браконьерство на диких животных.

В руководстве UNEP 2014 г., подготовленном опытными практикующими специалистами по концессиям для всех заинтересованных сторон (менеджеров, плановиков и персонала агентств по охраняемым территориям, для местных сообществ и для концессионеров, которые ведут свой бизнес на охраняемых территориях), концессия определяется как «аренда, лицензия, сервитут или разрешение на операцию, осуществляемую любой стороной, кроме агентства по охраняемым территориям» $[6$, с. 8$]$.

Авторы отчета в Секретариат Конвенции о биологическом разнообразии и Международный союз охраны природы (IUCN) A. Spenceley и другие под концессией понимают «право использовать землю или другое имущество для определенной цели, предоставленное правительством, компанией или другим контролирующим органом, включая коммерческую деятельность и/или участок земли» $[10$, с. 9].

В работе, выполненной под эгидой Всемирного банка ${ }^{1}$, отмечается, что официальным органам охраняемых территорий необходимо учитывать уровень предоставляемых на территории услуг, метод предоставления услуги, финансирование каждой услуги, а также то, осуществляются ли они самим Агентством или передаются на аутсорсинг. В последнем случае заключается договор с третьей стороной для оказания услуги.

\footnotetext{
${ }^{1}$ Tools and Resources for Nature-Based Tourism. World Bank, Washington, DC. (C) World Bank. URL: https://openknowledge.worldbank.org/handle/10986/34433 License: CC BY 3.0 IGO. 2020. 93 р. (дата обращения: 23.04.2021). Текст: электронный.
} 
Т. Б. Бардаханова, В. Д. Шаралдаева, Л. Б.-Ж. Максанова. Концессии в сфере туризма в национальных парках: особенности и этапы разработки

Что может привлечь потенциальных концессионеров? Это в первую очередь предоставление им права пользования объектами концессии и возможность получения из этого прибыли; уникальность и конкурентоспособность местности; упрощение доступа на территорию; возможность подключения к уже существующей туристической сети; наличие хорошей инфраструктуры, формирование законодательства, способствующего развитию туризма. Частный сектор, как правило, имеет меньше ограничений, чем государственный, и часто может предоставлять более качественные услуги и продукты $[2 ; 11]$.

Использование туристических концессий на ООПТ позволяет персоналу охраняемых территорий сосредоточиться на своей основной функции по сохранению биоразнообразия, и финансирование из государственных и других источников может быть использовано на природоохранную деятельность, а не на туризм [6]. Передача прав на использование земли другим организациям может избавить государственные учреждения от ресурсных ограничений, связанных с бюджетом, знанием рынка, возможностями или опытом.

Кроме того, концессии дают дополнительные источники доходов в виде сборов и арендной платы, которые также могут использоваться на финансирование охраняемой территории. Не менее важным преимуществом концессий является предложение дополнительных туристических услуг, товаров и инфраструктуры, которые администрация охраняемых территорий не может предоставить. В результате возможно увеличение потоков туристов, что, в свою очередь, способствует росту прямой и косвенной занятости местного населения, развитию новых возможностей для малого бизнеса. Таким образом, концессионная деятельность может обеспечить жизненно важную связь между местными сообществами, социально-экономическим развитием и сохранением биоразнообразия.

К наиболее существенным проблемам можно отнести сложность подготовки концессий и высокие требования к квалификации персонала, значительные затраты рабочего времени и недостаток полномочий охраняемой территории для решения всех возникающих вопросов. Кроме того, вся прибыль, полученная коммерческими концессионерами, может рассматриваться как потенциальный доход, упущенный «властью» охраняемой территории.

3.2 Основные компоненты и этапы разработки системы концессий для развития туризма в национальных парках

Закон о концессиях служит основой для определения параметров концессий на охраняемых территориях, а также помогает обеспечить гибкость концессионной системы для максимально эффективного функционирования. Ключевые моменты разработки системы концессий в национальных парках заключаются в следующем [6]:

- система концессий должна быть построена для достижения приоритетных и ранжированных целей развития туризма в балансе с целями сохранения охраняемой территории;

- законы, регулирующие концессии, должны предусматривать рамки коммерческой деятельности и содержать конкретные ограничения только в случае необходимости;

- более конкретные детали того, как действовать концессии, должны быть отражены в подзаконных актах и регулирующих воздействиях, обеспечивающих максимальный уровень эксплуатационной детализации; 
- закон, регулирование и политика должны быть понятны всем заинтересованным сторонам, а их разработка осуществляться в рамках публичного процесса с их участием;

- концессионная система состоит из ряда взаимосвязанных компонентов, от управления персоналом до законодательства и политики, процессов присуждения контрактов, ИТ-систем и мониторинга. Концессионная система должна специально разрабатываться, пересматриваться и совершенствоваться со временем.

На рисунке 1 показаны основные компоненты концессионной системы.

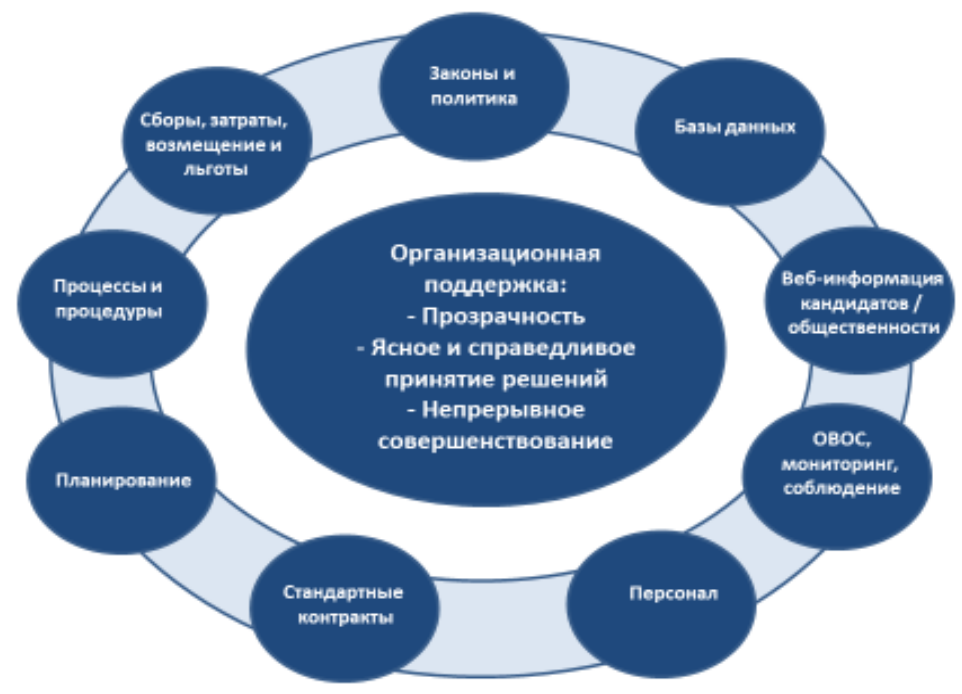

Рис. 1. Компоненты успешной системы концессий Источник: адаптировано авторами на основе [6]

Чтобы определить наиболее важные цели концессионной системы и их приоритетность, орган управления должен обозначить, что актуально для охраняемой территории. Если в контексте сохранения наследия охраняемых территорий основной целью является получение дохода от охраняемых территорий, то концессии могут быть предоставлены на открытом рынке через процесс открытых торгов или аукциона.

Если целью является расширение экономических возможностей для местного населения, то сообществам, живущим вокруг охраняемых территорий, могут быть предоставлены концессии, и агентство по охраняемым территориям может помочь им облегчить эту возможность, например, путем поиска туристического оператора для выстраивания партнерских отношений.

Тематические исследования из США, Намибии, Монголии и других стран показывают, как разные страны совершенствуют свои концессионные системы, в том числе правовые и политические рамки, чтобы добиться лучших экологических, социальных и экономических результатов от охраняемых территорий и их концессионных систем [6].

Так, в результате принятия в 1998 г. Закона о совершенствовании управления услугами концессий национальных парков вместо Закона о политике концессий 
Т. Б. Бардаханова, В. Д. Шаралдаева, Л. Б.-Ж. Максанова. Концессии в сфере туризма в национальных парках: особенности и этапы разработки

от 9 октября 1965 г. Служба национальных парков США (UN NPS) существенно изменила управление своей программой концессий и отношениями с концессионерами. Более короткие сроки контракта привели к улучшению обслуживания посетителей. Контракты отражают фактическую стоимость бизнеса и возвращают правительству значительно более высокие комиссионные за франшизу, при этом контролируя ставки, взимаемые с посетителей, и предоставляя концессионерам справедливую возможность получения прибыли. Техническое обслуживание объектов значительно улучшилось благодаря более эффективному мониторингу со стороны сотрудников UN NPS, которые повысили свои навыки управления активами.

Независимо от того, насколько мала или велика система, все компоненты системы концессий (рис. 1) должны в той или иной степени присутствовать. При этом стандартные контракты, веб-информация, подходы и процессы планирования, оценка воздействия на окружающую среду (ОВОС) и мониторинг всегда будут необходимыми компонентами концессионных работ.

Следует также рассмотреть дополнительные компоненты, такие как помощь концессионерам в интерпретации природоохранных ценностей для своих клиентов. Часто упускаемый из виду, но важный компонент управления концессией это уровень квалификации персонала. Персоналу концессионного предприятия требуется широкий спектр навыков, включая понимание процессов ОВОС, знание того, как работает туризм, и, что наиболее важно, навыки хороших взаимоотношений. Эти навыки необходимо развивать и сохранять.

Последовательность и содержание работ по подготовке и предоставлению туристических концессий в национальных парках представлена на рис. 2.

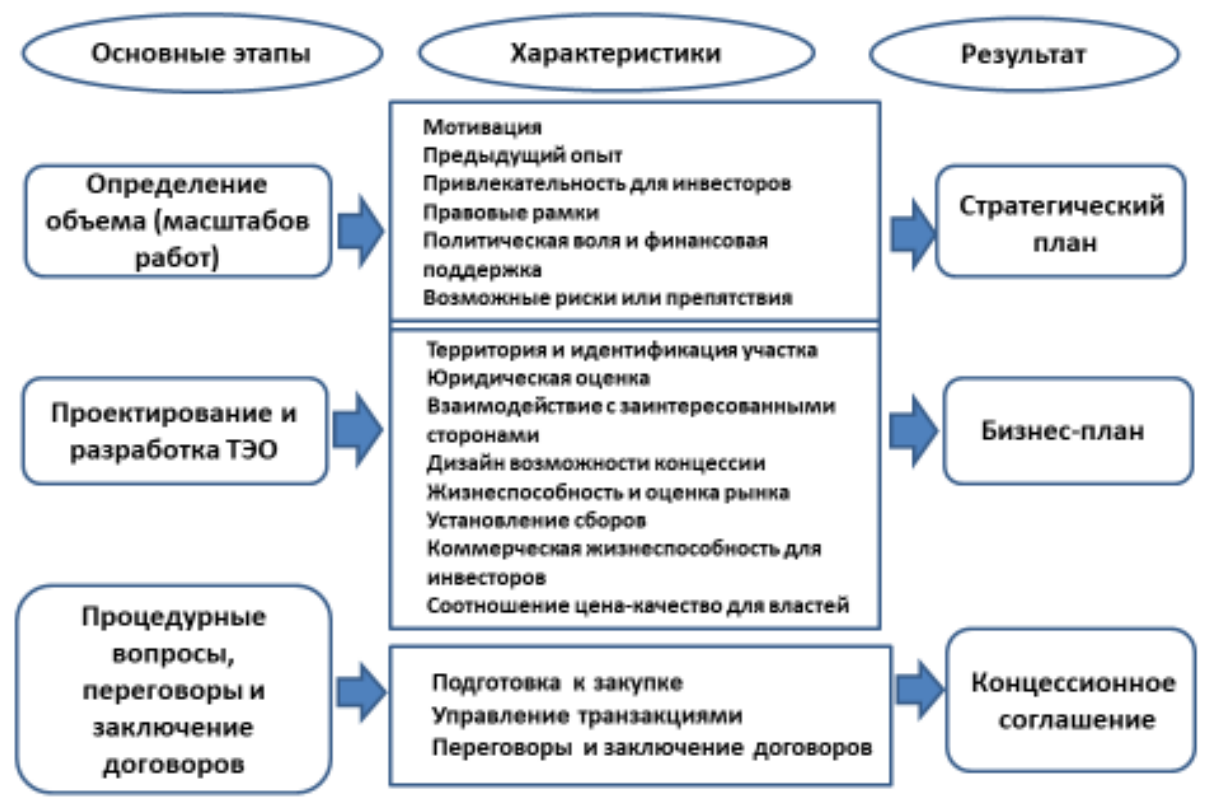

Рис. 2. Общие этапы и содержание работ по подготовке туристских концессий в национальных парках (источник: адаптировано авторами на основе [10]) 
Целью первого этапа работ является определение актуальности применения туристических концессий для конкретного национального парка. Результатом этапа должна явиться оценка готовности национального парка для инвестиций в туризм на основе концессий в формате стратегического плана со справочной информацией о правовой базе и институциональных структурах; инвестиционных предложениях частного сектора; оценкой территорий, подлежащих рассмотрению для инвестиций частного сектора, и их привлекательности и пр.

Цель второго этапа работ - определить, как будет выглядеть программа концессий в сфере туризма, включая доступные участки, туристические продукты для продвижения, потенциальные рынки и наиболее благоприятный тип модели концессии для использования. Эта фаза должна привести к разработке бизнесплана для программы концессии (рис. 3).

- Цели и задачи концессии

- Продукты и услуги, которые необходимо разработать, чтобы они были совместимы с экологической и социальной уязвимостью территории.

- Модель концессии (т. е. управление, аренда, строительство - эксплуатация передача и т. д.) с ролями и обязанностями органа управления и концессионера.

- Бизнес-модель (например, частный сектор, совместное предприятие, общественное предприятие).

- Анализ отрасли и рынка, включая предложение, международный, региональный и внутренний спрос, а также анализ конкурентов и рисков.

- Воздействие на развитие с точки зрения генерируемых доходов, созданных рабочих мест, мобилизации инвестиций, защиты природных ресурсов, развития навыков и местного экономического развития.

- План устойчивого развития, включая прямые и косвенные социальноэкономические и культурные связи с местными сообществами, сохранение биоразнообразия и управление окружающей средой.

- График проекта, включая любой поэтапный подход к реализации возможностей, жизненный цикл каждой концессии, включая процесс закупок, продолжительность и выход.

- Маркетинговый план, включая продукт, цену, продвижение, место и роли различных агентств.

- Финансовый план и прогнозы, включая лучшие, средние и худшие сценарии.

- Критические риски и предположения (например, финансовые, политические, экологические, социальные, репутационные, рыночные) и план смягчения последствий.

- Мониторинг и оценка концессии.

Рис. 3. Структура и содержание бизнес-плана для концессии (источник: адаптировано авторами на основе [10])

При подготовке концессий органу управления охраняемой территорией необходимо обратить внимание на следующие вопросы:

- правовое обеспечение: не поддерживающая, неясная правовая база отпугнет инвесторов;

- размер и расположение земли, предполагаемой к сдаче в концессию: определение размера (площади) и местоположения земельного участка относительно 
Т. Б. Бардаханова, В. Д. Шаралдаева, Л. Б.-Ж. Максанова. Концессии в сфере туризма в национальных парках: особенности и этапы разработки

другой инфраструктуры и услуг (дороги, электроснабжение, маршруты, границы охраняемой территории и т. п.);

- инфраструктурное обеспечение: администрациям ООПТ часто бывает сложно обеспечить обеспечивающую инфраструктуру для обслуживания туризма, например, дороги, водопровод, связь и т. д.;

- спрос на туристские предложения ООПТ, поскольку туризм может быть сезонным и нестабильным, на него влияют политические, природные, экономические факторы;

- финансовые ограничения: невозможность найти достаточную финансовую поддержку для процесса концессии в сфере туризма;

- сборы и сроки: частному партнеру должна быть предложена разумная структура вознаграждения и срок (период времени) концессии.

Третий этап концессионного процесса включает подготовку к закупке (включая стратегию и пакет, рекламные материалы и тендерные документы) и сам процесс переговоров. Этот этап должен привести к подписанию согласованного концессионного соглашения между администрацией охраняемой территории и инвестором.

3.3 Первоочередные предложения и рекомендации по подготовке и применению кониессионных соглашений в сфере туризма в начиональных парках России.

Согласно федеральному закону от 21.07.2005 № 115-Ф3 «О концессионных соглашениях» (п.1 ст. 3) специфика концессии заключается в том, что собственность на имущество, определенное концессионным соглашением, принадлежит концеденту, который вправе на определенных условиях передавать концессионеру права на имущество на определенный срок для его создания и (или) реконструкции полностью или частично за свой счет и осуществлять деятельность, предусмотренную концессионным соглашением, с использованием (эксплуатацией) объекта концессионного соглашения. После окончания срока действия концессионного соглашения концессионер обязан передать концеденту объект концессионного соглашения и иное предусмотренное концессионным соглашением созданное или реконструированное имущество (п. 1 ст. 14 115-ФЗ).

Концессионное соглашение представляет собой гражданско-правовой договор, характеризующийся рядом отличительных признаков (субъектный состав; объект концессионного соглашения; особая цель, связанная с осуществлением деятельности с использованием (эксплуатацией) объекта концессионного соглашения и особый порядок заключения концессионного соглашения) [9]. Предмет концессионного соглашения имеет смешанный характер и включает в себя имущество, подлежащее созданию или реконструкции концессионером, работы по его созданию или реконструкции, а также деятельность, осуществляемую концессионером с использованием этого имущества [13].

Исследователи считают, что именно концессии являются формой государственно-частного партнерства, которая в наибольшей степени соответствует особому статусу национальных парков в России $[8 ; 14]$. Применение концессий для развития туризма в национальных парках исключит изъятие объектов и земельных участков под ними из состава национального парка и позволит превратить использование уникальных природных ресурсов в экономический ресурс территории без изменения существующих границ национальных парков. 
Вместе с тем действующим законодательством не определена роль национального парка как особого участника ГЧП и отсутствуют нормы о возможности передачи частному партнеру или концессионеру объектов инфраструктуры, находящихся под управлением федерального государственного бюджетного учреждения. Поэтому первоочередным направлением в формировании системы концессионных соглашений в сфере туризма в национальных парках России является внесение изменений в действующее законодательство.

По мнению авторов, вторым по значимости направлением развития туристических концессий в национальных парках России являются планирование прибыльности концессий на основе анализа множества потенциальных видов туристической деятельности, которые могут иметь место на охраняемых территориях, и проведение оценки соответствия туристических продуктов рыночному спросу. Доходы от концессий зависят от способности частного сектора привлекать туристов в конкретный национальный парк, что, в свою очередь, определяется местоположением парка, его доступностью и возможностями предложения услуг, которые посетители готовы оплатить и могут покрыть стоимость эксплуатационных расходов. Общепринятым способом определения того, может ли концессия быть прибыльной, является разработка технико-экономического обоснования и бизнес-плана, определяющего, что, где и как можно развивать туризм.

Не менее важным направлением в настоящее время для национальных парков России является подготовка персонала для работы с туристическими концессиями в связи со сложностью подготовки концессий и высокими требованиями к квалификации персонала, а также нехваткой специалистов и значительными затратами рабочего времени. Проблемы и риски реализации концессий на ООПТ России являются недостаточно исследованными и могут стать источниками конфликтов и угроз при реализации инвестиционных проектов. Поэтому при организации взаимовыгодного партнерства полезны и важны рекомендации на основе передовых практик туристических концессий на охраняемых территориях, которые соответствуют национальному и местному контексту и текущим условиям конкретной страны, в которой предполагается их использование.

\section{4 Выводы}

1. Опыт передовых практик показывает, что туристические концессии на охраняемых территориях могут быть успешными при их правильном планировании и организации.

2. Правовая база для концессий устанавливает пределы, когда они могут быть разрешены для оказания ряда необходимых услуг, если это согласуется с сохранением территории. Она должна быть создана на прочной основе хорошо разработанных законов и государственной политики, связанных с охраняемыми территориями.

3. Первоочередными направлениями развития системы концессий в национальных парках России являются внесение изменений в действующее законодательство, позволяющее применять туристические концессии в национальных парках; формирование системы планирования прибыльности туристических концессий; повышение квалификации персонала органа управления охраняемой территорией по работе с потенциальными концессионерами. 
Т. Б. Бардаханова, В. Д. Шаралдаева, Л. Б.-Ж. Максанова. Концессии в сфере туризма в национальных парках: особенности и этапы разработки

4. Использование концессионных механизмов в работе с частным сектором связано как с выгодами, так и затратами. Тем не менее успех в сохранении природы и получении прибыли в туристических концессиях взаимосвязан, поэтому партнерские отношения, вероятно, принесут больше выгод для обеих сторон в долгосрочной перспективе.

\section{Литература}

1. Устойчивый туризм на охраняемых природных территориях. Руководство по планированию и управлению / П. Иглс [и др.]. Москва, 2006. 188 с. Текст: непосредственный.

2. Tourism and visitor management in protected areas: Guidelines for sustainability / Leung Yu-Fai (et. al.) // Best Practice Protected Area Guidelines Series. 2018. No. 27. Gland, Switzerland: IUCN. xii + 120 pp. URL: https://doi.org/10.2305/IUCN.CH.2018.PAG.27.en (дата обращения: 23.04.2021). Текст: электронный.

3. Андреева А. М., Максанова Л. Б.-Ж., Харитонова О. Б. Государственно-частное партнерство на особо охраняемых природных территориях: зарубежный опыт // Вестник Национальной академии туризма. 2020. № 3(55). С. 51-52. Текст: непосредственный.

4. Leonard Gilroy, Harris Kenny and Julian Morris Parks 2.0: Operating State Parks Through Public-Private Partnerships. Reason Foundation. 2013. 173 p. URL: https://reason.org/wp-content/uploads/files/state_parks_privatization.pdf (дата обращения: 23.04.2021). Текст: электронный.

5. Моисейкин В. Ф. Особенности национальных парков мира по формам собственности и организационной структуре // Вестник Национальной академии туризма. 2017. № 1. C. 16-22.

6. Tourism concessions in protected natural areas: Guidelines for managers / Thompson A., Massyn P. J., Pendry J., Pastorelli J. United // Nations Development Program www.undp.org/content/undp/en/home/librarypage/environment-energy/ecosystems_and_biodiversity/tourismconcessions-in-protected-natural-areas.html (дата обращения: $\overline{2}_{23.0 \overline{4}} 2021$ ). Текст: электронный.

7. Шаралдаева В. Д., Максанова Л. Б.-Ж., Шарафанова Е. Е. Государственно-частное партнерство в сфере туризма в России: состояние и особенности // Известия СанктПетербургского государственного университета. 2020. № 3 (123). С. 79-86. Текст: непосредственный.

8. Максанова Л. Б.-Ж., Шаралдаева В. Д., Андреева А. М. Правовые основы ГЧП для развития экологического туризма на ООПТ // Вестник Бурятского государственного университета. Экономика и менеджмент. 2020. № 4. С. 111-117. Текст: непосредственный.

9. О концессионных соглашениях: комментарий к федеральному закону от 21 июля 2005 г. № 115-Ф3 / Т. А. Кухаренко [и др.]. Доступ из справ.-прав. системы «КонсультантПлюс». URL: https://depzhkh.tomsk.gov.ru (дата обращения: 23.04.21). Текст: электронный.

10. Spenceley A., Snyman S. \& Eagles, P. Guidelines for tourism partnerships and concessions for protected areas: Generating sustainable revenues for conservation and development. Report to the Secretariat of the Convention on Biological Diversity and IUCN. 2017. 60 p. Текст: непосредственный.

11. Eagles P.F.J. Trends in Park Tourism: Economics, Finance and Management // Journal of Sustainable Tourism. 2002. 10 (2). P. 132-153.

12. Широков С. Н. Правовая сущность концессионного соглашения: автореферат диссертации на соискание ученой степени кандидата юридических наук. Челябинск, 2012. 32 с. Текст: непосредственный.

13. Воротников А. М., Доронин Н. С. Государственно-частное партнерство - механизм развития экологического туризма на особо охраняемых территориях Арктической 
зоны Российской Федерации // Менеджмент и бизнес-администрирование. 2019. № 4. С. 87-96. Текст: непосредственный.

Статья поступила в редакиию 30.06.2021; одобрена после рецензирования 30.07.2021; принята к публикациии 18.08.2021.

\section{TOURISM CONCESSIONS IN NATIONAL PARKS: THE PECULIARITIES AND STAGES OF DEVELOPMENT}

Taisiya B. Bardakhanova

Dr. Sci. (Econ.), Leading Researcher,

Baikal Institute of Nature Management SB RAS

8 Sakhyanovoy St., Ulan-Ude 670047, Russia

tbard@binm.ru

Viktoria D. Sharaldaeva

Cand. Sci. (Biol.), A/Prof.,

East-Siberian State University of Technology and Management

40v Klyuchevskaya St., Ulan-Ude 670013, Russia

sharvd@mail.ru

Lyudmila B.-Zh. Maksanova

Dr. Sci. (Econ.), A/Prof., Senior Researcher

Baikal Institute of Nature Management SB RAS

8 Sakhyanovoy St., Ulan-Ude 670047, Russia

lmaksanova@yandex.ru

Abstract. The article considers the peculiarities of tourist concessions in national parks, key points and components of the concession system based on adaptation of a number of analytical materials and manuals for managers, as well as a summative experience of the best practices of foreign countries in use of concessions in tourism in protected areas. We have studied the problems, strengths and weaknesses of the existing practices of using concession mechanisms, various aspects of planning and managing concession activities to maximize financial, economic and social benefits from working with the private sector to achieve the goals of biodiversity conservation in the long term. There are three main stages distinguished by different goals and content of work: 1) determination of the scope of work in a particular national park; 2) development of a concession program and a feasibility study; 3) preparation for procurement (including strategy and package, promotional materials and tender documents) and the negotiation process itself. We have formulated the top priority recommendations for the development of a reliable system of concessions in the field of tourism in national parks of Russia.

Keywords: public-private partnership; concessions; concession agreements; national park.

For citation

Bardakhanova T. B., Sharaldaeva V. D., Maksanova L. B.-Zh. Tourism Concessions in National Parks: the Peculiarities and Stages of Development. Bulletin of Buryat State University. Economy and Management. 2021; 3: 8-18 (In Russ.).

Acknowledgements. The study was carried out with the financial support of the Russian Foundation for Basic Research under the scope of the scientific project No. 20-010-00665.

The article was submitted 30.06.2021; approved after reviewing 30.07.2021; accepted for publication 18.08.2021. 